\title{
Comunicação/Communication
}

\section{Soropositividade para doença de Chagas entre doadores de sangue em Araraquara, Estado de São Paulo, no período de 2004 a 2008}

\author{
Seropositivity for Chagas disease among blood donors in Araraquara, State of São Paulo, \\ between 2004 and 2008
}

Julio César Rente Ferreira Filho ${ }^{1,2}$, Paulo Inácio da Costa ${ }^{3}$, Arnaldo Buainain ${ }^{3,4}$ e João Aristeu da Rosa ${ }^{2}$

\begin{abstract}
RESUMO
Introdução: A transfusão sanguínea é uma fonte potencial importante para transmissão da doença de Chagas. Métodos: Foi verificado, nos arquivos do Hemonúcleo Regional de Araraquara, o resultado dos exames para doença de Chagas entre janeiro de 2004 e dezembro de 2008. Resultados: Foram diagnosticadas com sorologia positiva 0,04\% das 49541 doações de sangue realizadas. A idade dos soropositivos situou-se entre 51 e 60 anos. Conclusões: O baixo índice de doadores soropositivos pode reduzir o risco de transmissão via transfusional da doença de Chagas. A alta ocorrência de resultados inconclusivos indicam que os métodos diagnósticos devem ser melhorados.
\end{abstract}

Palavras-chaves: Doença de Chagas. Epidemiologia. Transfusão sanguínea.

\section{ABSTRACT}

Introduction: Blood transfusion is an important potential source of Chagas disease transmission. Methods: Files from the Araraquara Regional Blood Center were checked regarding the tests results for Chagas' disease between January 2004 and December 2008. Results: Positive serology was diagnosed in $0.04 \%$ of 49,541 blood donations that were performed. Seropositive individuals were aged between 51 and 60 years-old. Conclusions: The low rate of seropositive donors may reduce the risk of transfusion transmission of Chagas disease. The high occurrence of inconclusive results indicates that the diagnostic methods must be improved.
\end{abstract}

Keywords: Chagas disease. Epidemiology. Blood transfusion.

A doença de Chagas, descrita por Carlos Chagas em 1909, ainda é uma das mais importantes questões de saúde pública que atinge a América Latina. Ela representa uma ameaça para, aproximadamente, 80 milhões de pessoas ${ }^{1}$ sendo que existem cerca de 15 milhões de infectados entre o México, ao norte e Chile, e Argentina ao sul, ocasionando 12.500 mortes por $\mathrm{ano}^{2}$.

A infecção dos seres humanos e outros vertebrados, como roedores, carnívoros, primatas, entre outros, ocorre prioritariamente

1. Programa de Pós-Graduação em Biociências e Biotecnologia Aplicada à Farmácia, Faculdade de Ciências Farmacêuticas, Universidade Estadual Paulista, Araraquara, SP. 2. Laboratório de Parasitologia, Departamento de Ciências Biológicas, Faculdade de Ciências Farmacêuticas, Universidade Estadual Paulista, Araraquara, SP. 3. Departamento de Análises Clínicas, Faculdade de Ciências Farmacêuticas, Universidade Estadual Paulista, Araraquara, SP. 4. Laboratório Dr. Arnaldo Buainain, Araraquara, SP.

Endereço para correspondência: Dr. Julio César Rente Ferreira Filho. Laboratório de Parasitologia/Dept ${ }^{\circ}$ de Ciências Biológicas/FCF/UNESP. Rod. Araraquara-Jaú Km 1, Caixa Postal 502, 14801-902 Araraquara, SP.

Tel: 55 163301-6945

e-mail: julio_crff@yahoo.com.br

Recebido para publicação em 28/12/2009

Aceito em 11/08/2010 pelo contato da pele e mucosa do hospedeiro vertebrado com as fezes do triatomíneo contaminado por Trypanosoma cruzi. Entretanto, há outras formas de transmissão: via transfusão sanguínea, congênita, por acidentes laboratoriais, por meio de transplante de órgãos e transmissão via oral ${ }^{3}$.

Este estudo mostrou os índices de soropositividade entre os doadores de sangue do Hemonúcleo Regional de Araraquara, os pacientes de um laboratório de análises clínicas público e um particular, e as notificações de doença de Chagas aguda na região de Araraquara, entre janeiro de 2004 e dezembro de 2008.

$\mathrm{O}$ delineamento para esta investigação consistiu em verificar o resultado do diagnóstico sorológico para doença de Chagas e a idade dos indivíduos, nos arquivos dos doadores de sangue do Hemonúcleo Regional de Araraquara, que atende, aproximadamente, vinte cidades vizinhas, dos pacientes do Núcleo de Atendimento à Comunidade (NAC), da Faculdade de Ciências Farmacêuticas (FCF), da Universidade Estadual Paulista (UNESP) de Araraquara, e dos pacientes de um laboratório particular, entre janeiro de 2004 e dezembro de 2008.

Também, foram avaliados junto ao Sistema de Informação de Agravos de Notificação (SINAN) os casos notificados de doença de Chagas aguda no referido período da pesquisa para as Cidades de Américo Brasiliense, Araraquara, Borborema, Descalvado, Dobrada, Gavião Peixoto, Motuca, Nova Europa, Rincão, Santa Lúcia e Taquaritinga.

No laboratório particular, foram utilizadas as técnicas de hemaglutinação indireta (HAI) e imunofluorescência indireta (IFI), e no hemonúcleo e laboratório público foram utilizados ELISA (enzyme linked immuno sorbent assay) e $\mathrm{HAI}^{4-6}$. Quando os resultados obtidos por meio dos dois exames foram discordantes, considerou-se o resultado inconclusivo, e então, foi realizado um terceiro método confirmatório, ELISA no laboratório particular e IFI no hemonúcleo e no laboratório público. O resultado foi considerado reagente quando os dois métodos apresentaram resultado positivo.

O laboratório particular utilizou o IMUNOCRUZI® (BiolabMérieux, Rio de Janeiro, Brasil) para realizar o teste de IFI e o kit de um distribuidor regional sem especificação para o teste de HAI. O kit utilizado pelo hemonúcleo e o laboratório público para realização da HAI foi o Imuno-HAI Chagas (WAMA Diagnóstica), e o utilizado para o teste de ELISA foi o ELISA CHAGATEK ${ }^{\circledR}$ (Biolab-Mérieux, Rio de Janeiro, Brasil). As bulas dos métodos de diagnóstico indicaram a utilização de antígenos purificados de T. cruzi para realização dos testes, sem especificação da cepa, forma do parasita e localização do antígeno. 
Os doadores e pacientes dos laboratórios foram divididos em faixas etárias para avaliação da distribuição de soropositividade por meio do programa Excel da Microsoft. Para a análise estatística, foi utilizado o teste não paramétrico do qui-quadrado, o nível de significância considerado foi $\mathrm{p}<0,05$.

No laboratório particular, foram realizados 732 exames sorológicos para diagnóstico da doença de Chagas, desses, 77 (10,5\%) foram reagentes e 42 (5,7\%) inconclusivos. No laboratório público, da Faculdade de Ciências Farmacêuticas/UNESP, Araraquara, realizaram-se, 1.723 exames para diagnóstico sorológico da doença de Chagas, sendo que 251 (14,5\%) tiveram resultado reagente; entretanto, os resultados inconclusivos não foram disponibilizados conforme está demonstrado na Tabela 1.

TABELA 1 - Resultado dos exames sorológicos para doença de Chagas, em porcentagem, entre 2004 e 2008 em Araraquara.

\begin{tabular}{|c|c|c|c|c|c|}
\hline & \multirow[b]{2}{*}{ Total de exames } & \multicolumn{2}{|c|}{ Reagentes } & \multicolumn{2}{|c|}{ Inconclusivos } \\
\hline & & $\mathrm{n}^{\mathrm{o}}$ & $\%$ & $\mathrm{n}^{\mathrm{o}}$ & $\%$ \\
\hline Hemonúcleo & 49.541 & 19 & 0,04 & 69 & 0,14 \\
\hline Laboratório particular & 732 & 77 & 10,5 & 42 & 5,7 \\
\hline Laboratório público & 1.723 & 251 & 14,6 & & * \\
\hline
\end{tabular}

Passaram pelo Hemonúcleo Regional de Araraquara 62.841 candidatos à doação, incluindo os de repetição. Desses, 13.300 $(21,2 \%)$ foram classificados como inaptos pela triagem e não puderam doar sangue, e 49.541 (78,8\%) realizaram doação nos últimos cinco anos. Dessas doações realizadas, 19 (0,04\%) foram diagnosticadas reagentes e $70(0,14 \%)$ apresentaram resultado inconclusivo para doença de Chagas, por isso essas bolsas foram descartadas.

A pesquisa de notificação de casos agudos nos municípios resultou no achado de um único caso em Araraquara no ano de 2006.

A idade dos doadores variou de 18 a 65 anos e dos doadores soropositivos para doença de Chagas, entre 39 e 57 anos. O intervalo de idade onde se encontravam os soropositivos para doença de Chagas situou-se entre 23 e 80 anos e a maior concentração ocorreu na faixa etária de 51 a 60 anos (Figura 1). A proporção de positivos, no grupo acima de 50 anos, foi significativamente superior à do grupo com idade igual ou inferior a 50 anos $(\mathrm{p}<0,0001)$.

A soropositividade de $0,04 \%$ encontrada no Hemonúcleo Regional de Araraquara é significativamente menor que à observada no Hemocentro de Pelotas ${ }^{7}$ com 0,5\%, entre 2004 e 2005, diagnosticada pelo teste ELISA. Também é menor que 1,9\%

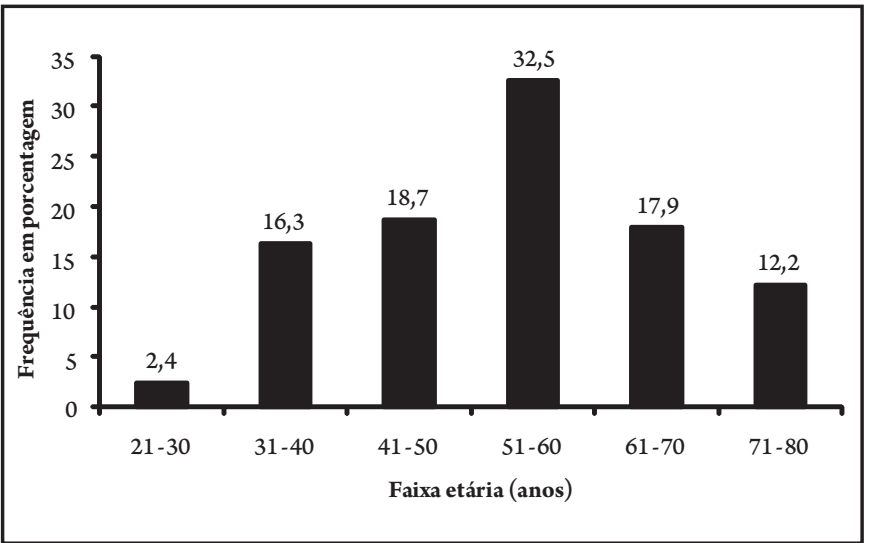

FIGURA 1 - Frequência de idade dos pacientes soropositivos para doença de Chagas, em Araraquara-SP, entre 2004 e 2008. de soropositividade detectada na região endêmica de Iguatu/ $\mathrm{CE}^{8}$, entre 2006 e 2007, por meio dos métodos ELISA e hemaglutinação passiva reversa. Nos Estados Unidos ${ }^{9}$, entre agosto de 2006 e janeiro de 2007, foram encontrados 32 doadores soropositivos dentre os 148.969 pesquisados; porém, os métodos imunológicos não foram informados.

A baixa soropositividade encontrada no Hemonúcleo Regional de Araraquara pode ser justificada por essa ser uma região nãoendêmica para doença de Chagas e pela refinada triagem realizada junto aos pacientes antes da doação, haja vista a grande porcentagem $(21,2 \%)$ de pacientes considerados inaptos a doar sangue.

Uma possível explicação para o maior índice de soropositividade encontrado nos laboratórios de análises clínicas em relação ao hemocentro, $10,5 \%$ no laboratório particular e $14,5 \%$ no público, é que os laboratórios realizam diagnóstico para doença de Chagas nos trabalhadores oriundos de regiões endêmicas, que trabalham na safra da cana-de-açúcar e da laranja em Araraquara, especialmente entre os meses de maio e agosto de cada ano. Também, é importante considerar que nos laboratórios de análises clínicas, os exames sorológicos são feitos mediante solicitação médica, enquanto no hemonúcleo, são feitos em todos doadores, o que aumenta a probabilidade de soropositivos encontrados nos laboratórios.

O laboratório público apresenta maior índice de soropositividade que o laboratório privado provavelmente porque atende uma população com menor renda, muitas vezes oriunda de regiões endêmicas. Além disso, são realizados exames sorológicos para doença de Chagas no acompanhamento pré-natal de todas as gestantes que passam pelo serviço público de saúde, isso aumenta o número de pacientes soropositivos diagnosticados ao acaso.

Os kits utilizados para o diagnóstico da doença de Chagas empregam antígenos do T. cruzi obtidos de cepas e formas variadas do parasita. Os anticorpos que reagem com esses podem reagir com antígenos de outras patologias como Leishmania $s p^{10-12}$ conferindo reação cruzada. Isso diminui a especificidade dos exames de diagnóstico para doença de Chagas, podendo ser a causa dos resultados inconclusivos encontrados. Esse problema seria solucionado se os exames utilizassem antígenos específicos e presentes nas mais diversas cepas e formas de T. cruzi.

A ocorrência de soropositivos para doença de Chagas, em maioria na faixa etária entre 51 e 60 anos de idade, pode ser um indicador que não ocorreu incidência de doença de Chagas em Araraquara entre 2004 e 2008.

\section{AGRADECIMENTOS}

A Christiane Barbosa Viola, Jussara Helena Camparis Lessi, Maria Inês da Silva e Tatiana Zampiero Ramos Pollis por colaborarem no fornecimento dos prontuários, e também ao Dr. Julio César Mine e a Maria Fernanda Falcone Dias pela leitura crítica e auxílio na revisão do trabalho.

\section{CONFLITO DE INTERESSE}

Os autores declaram não haver nenhum tipo de conflito de interesse no desenvolvimento do estudo. 


\section{REFERÊNCIAS}

1. Coura JR, Dias JCP. Epidemiology, control and surveillance of Chagas disease 100 years after its Discovery. Mem Inst Oswaldo Cruz 2009; 104: 31-40.

2. Lazdins-Helds JK, Felipe G. Reporte del grupo de trabajo científico sobre la enfermedad de Chagas. Buenos Aires: World Health Organization; 2007.

3. Brener Z, Andrade ZA, Barral-Netto M. Trypanosoma cruzi e Doença de Chagas. $2^{a}$ ed. Rio de Janeiro: Guanabara; 2000.

4. Araújo AB, Vianna EES, Berne MEA.Anti-Trypanosoma cruzi Antibody Detection in Blood Donors in the Southern Brazil. Braz J Infect Dis 2008; 12:480-482.

5. Dias JCP, Brener S. Chagas disease and blood transfusion. Mem Inst Oswaldo Cruz 1984; 79:139-147.

6. Portela-Lindoso AAB, Shikanai-Yasuda MA. Doença de Chagas crônica: do xenodiagnóstico e hemocultura à reação em cadeia da polimerase. Rev Saude Publica 2003; 37:107-115.

7. Bornametti AM, Castelo-Filho A, Ramos LR, Baldy JLS, Matsuo T. Infecção por Trypanosoma cruzi em candidatos a doador de sangue. Rev Saude Publica 1998; 32:566-571.

8. Sobreira ACM, Gomes FVBAF, Silva MAMS, Oliveira MF. Prevalência de infecção chagásica em doadores de sangue do Hemocentro Regional de Iguatu, CE. Rev Soc Bras Med Trop 2001; 34:193-196.

9. Stramer SL, Dodd RY, Mascola L, Rosenberg LJ, Lawaczeck E, Montgomery S, et al. Blood Donor Screening for Chagas Disease. Morb Mortal Wkly Rep 2006-2007; 56:141-143.

10. Passos VMA, Volpini AC, Braga EM, Lacerda PAF, Ouaissi A, Lima-Martins MVC, et al. Differential Serodiagnosis of Human Infections Caused by Trypanosoma cruzi and Leishmania spp. Using ELISA with a Recombinant Antigen (rTc24). Mem Inst Oswaldo Cruz 1997; 92:791-793.

11. Melo AS, Lorena VMB, Moraes AB, Pinto MB, Gomes YM. The prevalence of chagasic infection among blood donors in the State of Pernambuco, Brazil. Rev Bras Hematol Hemoter 2009; 31:69-73.

12. Moraes-Souza H, Martins PRJ, Ferreira-Silva MM, Pereira GA. Perfil sorológico para doença de Chagas dos doadores de sangue do Hemocentro Regional de Uberaba. Rev Bras Hematol Hemoter 2006; 28:105-109. 